\title{
Multivariate mapping for experienced users: comparing extrinsic and intrinsic maps with univariate maps
}

\begin{abstract}
Multivariate mapping is a technique in which multivariate data are encoded into a single map. A variety of design solutions for multivariate mapping refers to the number of phenomena mapped, the map type, and the visual variables applied. Unlike other authors who have mainly evaluated bivariate maps, in our empirical study we compared three solutions when mapping four variables: two types of multivariate maps (intrinsic and extrinsic) and a simple univariate alternative (serving as a baseline). We analysed usability performance metrics (answer time, answer accuracy, subjective rating of task difficulty) and eye-tracking data. The results suggested that experts used all the tested maps with similar results for answer time and accuracy, even when using four-variable intrinsic maps, which is considered to be a challenging solution. However, eye-tracking data provided more nuances in relation to the difference in cognitive effort evoked by the tested maps across task types.
\end{abstract}

Keywords

Multivariate map $\bullet$ bivariate map $\bullet$ thematic mapping $\cdot$ user study $\cdot$ eye tracking

(c) University of Warsaw - Faculty of Geography and Regional Studies

\author{
Jolanta Korycka-Skorupa $\mathbb{C}$, \\ Izabela Gołębiowska đ] \\ Department of Geoinformatics, Cartography and Remote \\ Sensing, Faculty of Geography and Regional Studies, \\ University of Warsaw, Warsaw, Poland \\ e-mail: j.skorupa@uw.edu.pl \\ e-mail: i.golebiowska@uw.edu.pl \\ Received: 22 June 2021 \\ Accepted: 6 July 2021
}

Introduction

The main purpose of multivariate maps is to compare spatial distribution two or more phenomena (Slocum et al. 2010; Kraak et al. 2020). This solution enables the amount of information conveyed by a single map to be increased (Nelson 2020). It also helps users to find relationships between two or more phenomena that they are searching for or that they might not suspect are present. Multivariate maps are also a compact solution. They help to save space when designing maps: instead of preparing a series of maps, representing the same area but with different variables, a map maker may choose to produce a single multivariate map. However, multivariate maps are challenging for users due to visual complexity (Dent, Torguson \& Hodler 2009; Huber et al. 2007; Nelson 2020). Furthermore, multivariate maps are not often applied in popular media; therefore, a potential user may not be familiar with this kind of solution nor experienced in using it. As a result, users may be discouraged from further analysis of the (too) complex map. As Nelson (2020) noted, a map maker must thus balance the benefits and insights enabled by multivariate maps with expectations of the audience's ability and willingness to engage with the challenging map. Although many authors elaborated on multivariate mapping, empirical evidence with an in-depth insight into user visual behavior when using multivariate maps is still needed.

The aim of the study reported here is to evaluate the consequences of applying multivariate maps using two designs. Unlike other authors (mainly evaluating bivariate map options), we compared three solutions when mapping four variables: two types of multivariate maps and a simple univariate alternative (serving as a baseline). As widely proved, design matters (e.g. Kiik, Nyström \& Harrie 2017). Therefore, similar to Šašinka et al. (2019), we assumed that, depending on the form of multivariate visualisation, the resulting cognitive load will differ. We also expected the processing difficulty to be different for each of the multivariate combinations, based on selective attention theory (Nelson 2000b). Furthermore, we assumed that the task type also affects the results when using different multivariate maps. The different kinds of information (elementary or more complex) may be easier or more difficult to acquire depending on the multivariate map design and the number of variables encoded in a particular map. Due to the cognitive effort involved when decoding multivariate maps, we wanted to verify whether the effort connected with working with a single four-variate map is considerably more challenging than when working with a series of univariate maps. Furthermore, we wanted to get an insight into the studied process; we therefore decided to analyse basic eye-tracking metrics to support the analysis of the usability performance metrics.

\section{Design solutions for multivariate mapping}

There is a wide scope of choices of thematic map types, as well as involved graphic solutions. The options have more- or less-integrated visual variables to represent the mapped variables (Korycka-Skorupa \& Nowacki 2019). The variables can be designed in a separable way, applying inter-symbol encoding (Nelson 2020; see examples on Fig. 1 left). The resulting image is an extrinsic map (Šašinka et al. 2019, 2021). A straightforward combination of two or more variables represented by distinct, separable visual variables results in inter-symbol encoding in extrinsic maps. The 
two variables are shown concurrently on a single map, but each of them can also be presented independently on two separate maps. The most common combination is a choropleth map with a graduated/proportional symbols map.

Further visual integration of the visual variables when mapping multivariate data in a more challenging solution. The two mapped phenomena are visually inseparable by applying intra-symbol encoding (Nelson 2020a); thus, an intrinsic map is achieved (Gershon 1998; Šašinka et al. 2019, 2021; see Fig. 1 right). The most commonly applied example of an intrinsic map is a bivariate choropleth map, incorporating two colour scales into one.

E.S. Nelson (2000b) considered bivariate symbols in relation to selective attention, the approach developed in psychology. The author grouped sets of visual variables into those that support selective attention and those that fail to do so. The first category is called separable design and includes size-hue (e.g. applied to proportional circles with fills according to a sequential colour scheme) (Nelson 1999, 2000a). It is considered that the category of integral design does not support selective attention and does not facilitate the extraction of specific variable information. The design is created by applying, for example, value-saturation (for bivariate choropleth maps) or rectangle height and width. Nelson (2000b) also distinguished a category of configural design, which includes setting separable halves of circles to use with the following pairs of variables: size-size.

As listed above, there is a wide scope of available design solutions when mapping many variables, but they differ in terms of cognitive load for map users. It is claimed that multivariate maps, especially with intrinsic encoding, increases the cognitive abilities needed to read the map, and makes the presentation challenging for the users (Nelson, 2020). Therefore, users with high skills and map literacy may be considered an appropriate and suitable audience for this kind of mapping. When considering an alternative to the two multivariate options, extrinsic and intrinsic, an available solution might be to use a simpler approach, presenting a series of univariable maps of the same territory, each representing a different variable (Nelson, 2020). This approach is helpful when showing both separate variables or for presenting changes over time (Fabrikant et al. 2008; Tufte 1990). In the latter case, an animated map is also an available solution (Nelson, 2020).

Many authors have described and discussed various designs of multivariate maps (Brewer \& Campbell 1998; Carr 1991; Carr, Olson \& White 1992; Cuff, Pawling \& Blair 1984; Dahlberg 1981). Elmer (2013) developed a taxonomy of bivariate symbol solutions on the basis of visual variables and spatial reference (points/lines/ areas), and it included over 40 mapping solutions. Recently Strode et al. (2020) discussed multivariate mapping techniques suitable for visualising a vulnerability index: bivariate symbols, cartographic glyphs placed in multiple small cells to represent four variables, and Euler diagrams to depict overlap between the mapped variables.

When discussing multivariate mapping, a map user should also be taken into consideration. These kinds of maps are meant to support the comparison of phenomena. However, while working, a user may conduct various map reading operations: extract either correlational or individual information. Task types can also be distinguished based on how many variables they refer to (similar to the division of tasks applied in the study of Šašinka et al. 2021). Nelson (2000a, 2000b) used more detailed list of tasks: baseline, filtering, redundancy and condensation tasks. The baseline and filtering tasks focus on one specific variable. Baseline tasks require users to recognise one symbol, whereas filtering tasks involve distinguishing the searched variable among others presented. Redundancy and condensation tasks pinpoint a specific type of interaction between variables: redundantly

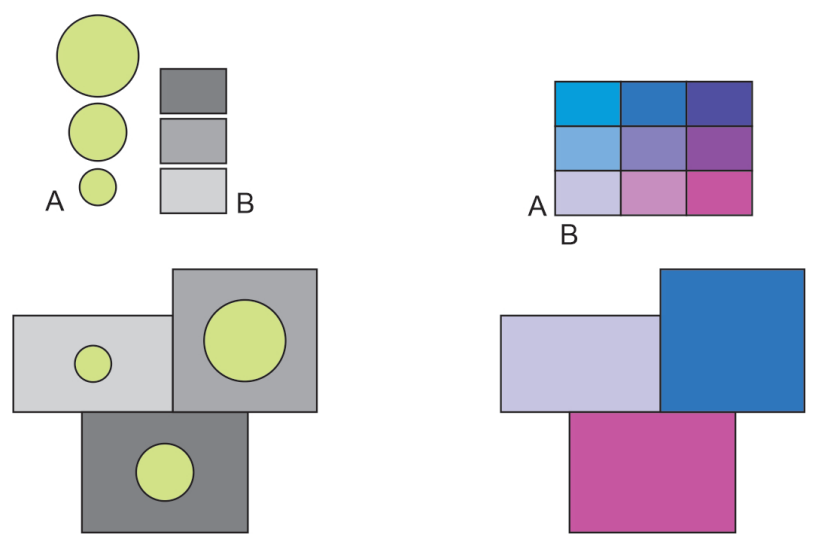

Figure 1. Two solutions when designing bivariate maps: extrinsic (left) and intrinsic (right)

Source: own elaboration

paired variables for the former, and changing independently for the latter. Therefore, when evaluating the different multivariate map types, the factor of task type should also be included.

\section{Previous evaluation of multivariate maps}

Multivariate mapping has been the subject of empirical evaluation. Bivariate choropleth maps have received the most attention while conducting empirical assessment (Carstensen 1982, 1984, 1986a, 1986b; Lavin and Archer 1984; Leonowicz 2006; Olson 1981; Šašinka et al. 2019, 2021). The research focuses on evaluating design solutions, such as an unclassed bivariate choropleth map using crossed-line shading (Lavin and Archer 1984) or on searching for factors affecting the interpretation of this map type - for example, users' abilities (Carstensen 1982), the operation to be conducted (Carstensen 1984, 1986a), or the applied scaling method (Carstensen 1986b). Efforts have been made in order to evaluate the intuitiveness of colour scale for bivariate choropleth maps (Olson 1981; Wainer \& Francolini 1980; Eyton 1984) often proving a color spectral scheme as not appropriate. Bivariate maps were also tested with regard to searching just noticeable differences - for example, for sector sizes on two-sectored pie charts (Slocum 1981).

Nelson conducted a series of experiments in order to test selective attention theory for bivariate symbols in abstract settings $(1999,2000 a)$ and in map settings (2000b). Selective attention theory assumes that the ability to analyse one symbol's visual variable, for example colour or size, is affected by another visual variable applied in the same symbol. The results collected by Nelson (1999, 2000a, 2000b) showed that answer times for baseline and redundancy tasks (that required attending to only one dimension while the second dimension was constant or attending to either dimension) are lower than for filter and condensation tasks (that required filter out an irrelevant dimension or to attending both varying dimensions). Furthermore, when assessing the perceptual grouping with regard to bivariate symbols in an abstract setting, Nelson (2000a) showed that most combinations of visual variables can be analysed separately by a map user. Combinations in which users could extract a particular separable variable included size/ hue, value/size, value/shape, and shape/hue, whereas symbol sets composed of homogeneous combinations (size/size, value/ value, hue/hue) resulted in a strong interaction. Also Elmer (2013) referred to selective attention theory when empirically testing eight bivariate map types. The study included the combination of extrinsic (choropleth and graduated symbols) as well as intrinsic (bivariate choropleth maps and rectangle) maps. These two designs (i.e. choropleth map with graduated symbols and 


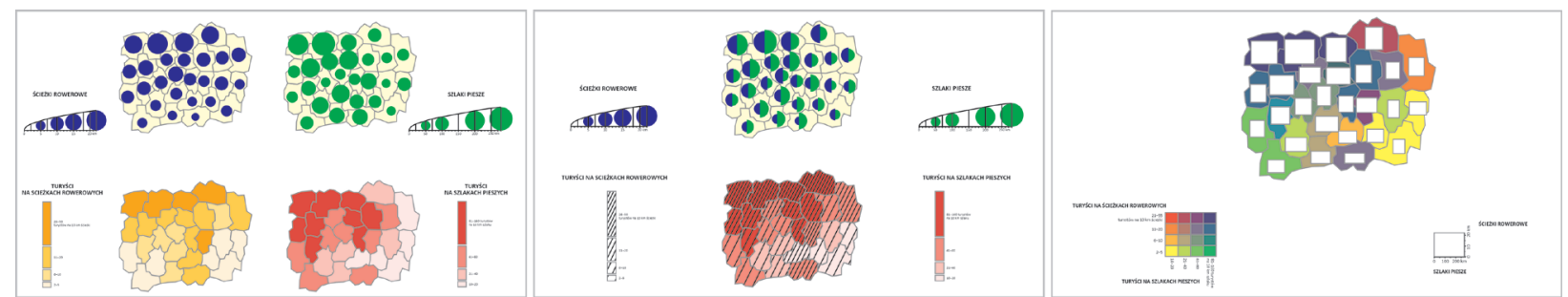

a) M1v

b) $\mathrm{M} 2 \mathrm{v}$

c) M4v

Figure 2. Examples of maps tested in the study Source: own elaboration

bivariate choropleth map) resulted in below average response times. Šašinka et al. (2019) tested whether the performance effects of two types of multivariate maps - intrinsic (bivariate choropleth map) and extrinsic (graduated symbols with choropleth map) were related with the cognitive global/local strategy. Moreover, the eye-tracking data analysis showed that intrinsic bivariate maps resulted in a higher share of time spent analysing the map legend than in the case of extrinsic maps. In the followup study, Šašinka et al. (2021) concluded that the intrinsic method required more time and led to higher error rates that extrinsic. The difference was less pronounced in the tasks that referred to both mapped variables.

The empirical research conducted shed light on how different bivariate maps affect the way users work. Authors of the previous studies acknowledged the impact of task types on the results while working with the multivariate maps. The studies aimed to compare different types of multivariate maps but did not involve a series of univariate maps as a baseline for the comparison.

\section{Empirical study}

Study design

The aim of the study is to compare three designs of decreasing cognitive complexity for mapping four variables: intrinsic map, extrinsic map and their alternative - a series of univariate maps. We focused on the impact of task type on users' performance when comparing the map options.

We wanted to verify if success in using a multivariate map is related to the task complexity, particularly in relation to the number of mapped phenomena included in a task (later called variables). We hypothesised that one four-variate map would be better for complex tasks, a bivariate map would be better for tasks of moderate complexity, whereas a univariate map would be suitable for simple tasks. Moreover, maps with separable variables applied should be more useful when data sets need to be accessed individually rather than when the task goal is to find data correlation. We also assume that the time required to extract information from a four-variate map is higher than the sum of times spent when solving the same task using four univariate maps.

In the empirical study we applied mixed factorial design with map type and task complexity as independent variables, and performance metrics (answer time, answer accuracy, eyetracking metrics) as the dependent variable. We applied withinsubject design. The study combines a confirmatory stage of the research (that was applied through analysis of usability performance metrics of answer time, answer correctness and rated difficulty) and an exploratory stage. Within the exploratory stage we analysed eye-tracking metrics in order to get an additional insight into the consequences of using different types of multivariate maps.
Materials and tasks

We tested three design solutions for mapping four variables (Fig. 2): (1) four univariate maps (Fig. 2a), (2) two bivariate maps (Fig. 2b), and (3) the four-variate map (Fig. 2c) applies intrinsic design with integral variables (as defined by Nelson 1999, 2000b): rectangle map with bivariate choropleth map. The two bivariate maps (Fig. 2b) represented extrinsic design with separable (choropleth map with crossed-line shading) and configural variables (proportional symbols as two halves of circles, each representing a different variable). Finally, univariate maps (Fig. 2a) were two choropleth maps and two proportional symbols maps. The map presented a fictitious area divided into 27 polygons. Due to within-subject design we prepared three sets of data mapped with the same spatial pattern. Each data set focused on tourism and consisted of four variables.

Each participant solved nine tasks of three levels of complexity regarding number of variables: three tasks referred to one variable $(\mathrm{T} 1 \mathrm{v})$, three tasks referred to two variables $(\mathrm{T} 2 \mathrm{v})$ and three tasks referred to four variables (T4v). The first type concerned the operation of extracting a single value, the second of localising an area according to the indicated values of two variables, and the third of finding the areas representing extreme values of all four variables. According to the types described by Nelson (2000a), they represented, respectively: filtering, condensation and redundancy tasks (see section 2 'Design solutions for multivariate mapping'; Table 2). In total there were four open and five closed questions.

In order to omit the learning effect the tasks were presented to each participant in a random order. We used an online tool, https://www.randomizer.org/, to randomise the sequence of tasks for each participant. A particular participant saw a set of data three times, but each time it was represented using different types of maps, and each time they solved different types of tasks (Fig. 3).

\section{Procedure and apparatus}

The experiment consists of several stages (Fig. 4). First, participants were informed about the general purpose of the study, and they signed consent forms. Then eye-tracker calibration and training on how to provide answers were conducted. In the next stage the participants solved the set of tasks. After each task, a participant rated the perceived difficulty of the given task. Finally, they filled out the questionnaire, providing background information and self-rating regarding their experience in the use of maps. The whole procedure took approximately 30 minutes.

The experiment was conducted on a MSI GV72 7RD laptop with a 17 inches screen size. The screen resolution was set to $1920 \times 1980$. The tasks were presented in the Chrome web browser. Eye-tracking data were recorded using a Tobii X120 eye-tracker (www.tobii.com). The recording resolution was set to $120 \mathrm{~Hz}$. The questions were presented next to the maps. 
MISCELLANEA GEOGRAPHICA - REGIONAL STUDIES ON DEVELOPMENT

Vol. 25 • No. 4 • 2021 • pp. 259-271 • ISSN: 2084-6118 • DOI: 10.2478/mgrsd-2020-0068

Table 1. Examples of questions asked in the study

\begin{tabular}{|c|c|c|c|c|}
\hline $\begin{array}{l}\text { Task } \\
\text { type }\end{array}$ & $\begin{array}{l}\text { Number of } \\
\text { variables in } \\
\text { the task }\end{array}$ & Question & Operation type & $\begin{array}{l}\text { Question } \\
\text { type }\end{array}$ \\
\hline \multirow{3}{*}{$\mathrm{T} 1 \mathrm{v}$} & \multirow{3}{*}{1} & Indicate the area visited by the least number of individual tourists. & \multirow{3}{*}{$\begin{array}{l}\text { extracting a } \\
\text { single value }\end{array}$} & open \\
\hline & & $\begin{array}{l}\text { What hotel room price per night is possible in the area marked with } \\
\text { symbol 'X'? } \\
\text { PLN 42.8/PLN 75.6/PLN 137.9/PLN } 332.2\end{array}$ & & closed \\
\hline & & $\begin{array}{l}\text { In which areas among those marked with letters are the trail lengths } \\
\text { the shortest? } \\
\text { A/B/C/D }\end{array}$ & & closed \\
\hline \multirow{3}{*}{$\mathrm{T} 2 \mathrm{v}$} & \multirow{3}{*}{2} & $\begin{array}{l}\text { What is the income from tourism in the area visited by the highest } \\
\text { number of tourists? } \\
\text { PLN } 7.5 \mathrm{~K}-10 \mathrm{~K} \text { per person/PLN } 10.1 \mathrm{~K}-15 \mathrm{~K} \text { per person/PLN } \\
15.1 \mathrm{~K}-25 \mathrm{~K} \text { per person/PLN } 25.1 \mathrm{~K}-47.5 \mathrm{~K} \text { per person }\end{array}$ & \multirow{3}{*}{$\begin{array}{l}\text { localising an } \\
\text { area according } \\
\text { to values of two } \\
\text { variables }\end{array}$} & closed \\
\hline & & $\begin{array}{l}\text { Indicate the area with the lowest hotel room price per night and, at } \\
\text { the same time, the lowest number of restaurants. }\end{array}$ & & open \\
\hline & & $\begin{array}{c}\text { Among areas with } 11-20 \text { tourists per } 10 \mathrm{~km} \text { of bike routes, indicate } \\
\text { the one with the shortest length of bike trails. }\end{array}$ & & open \\
\hline \multirow{3}{*}{$\mathrm{T} 4 \mathrm{v}$} & \multirow{3}{*}{4} & $\begin{array}{l}\text { In which group of areas marked with letters are the values of all } \\
\text { variables the lowest? } \\
\text { A/B/C/D }\end{array}$ & \multirow{3}{*}{$\begin{array}{l}\text { finding areas } \\
\text { representing } \\
\text { extreme values } \\
\text { of all four } \\
\text { variables }\end{array}$} & closed \\
\hline & & $\begin{array}{l}\text { Indicate the area with extreme (min or max) values of at least three } \\
\text { variables. }\end{array}$ & & open \\
\hline & & $\begin{array}{l}\text { Are there areas with the highest values for all four indices? } \\
\text { yes/no }\end{array}$ & & closed \\
\hline
\end{tabular}

Source: own elaboration

\begin{tabular}{rl|l|l|l|l|l|l|l|l|l|l|} 
& \multicolumn{3}{c}{ T4v } & \multicolumn{4}{c}{ T2v } & \multicolumn{3}{c}{ T1v } \\
\hline user: 1, 4, 7, 10, 13, 16 & M1v-A & M2v-B & M4v-C & M2v-A & M4v-B & M1v-C & M4v-A & M1v-B & M2v-C \\
\hline user: 2, 5, 8, 11, 14 & M2v-B & M4v-C & M1v-A & M4v-B & M1v-C & M2v-A & M1v-B & M2v-C & M4v-A \\
\hline user: 3, 6, 9, 12, 15 & M4v-C & M1v-A & M2v-B & M1v-C & M2v-A & M4v-B & M2v-C & M4v-A & M1v-B \\
\hline
\end{tabular}

Map type:

Topic of mapped data:

M1v four maps: each presenting one variable

A tourism

M2v two maps: each presenting two variables

B hotels \& restaurants

M4v

one map presenting four variables

C bike routes/trails

Figure 3. The sets of maps and task solved by each participant (a participant was randomly assigned to a set) Source: own elaboration

\section{Participants}

In total, 16 participants took part in the study; there was an equal number of each sex ( $50 \%$ female, $50 \%$ male); they were aged from 24 to 30 years (26.6 on average). Since it is assumed that multivariate maps are a challenging solution, we decided to recruit only participants with a high level of map literacy, who were experienced in map reading and interpretation. All of the participants graduated with a master's degree, majoring in Geoinformatics, cartography and remote sensing at the Faculty of Geography and Regional Studies, University of Warsaw. $93.3 \%$ of participants declared using and making maps in their professional work; the same share declared using maps at least once a month. 


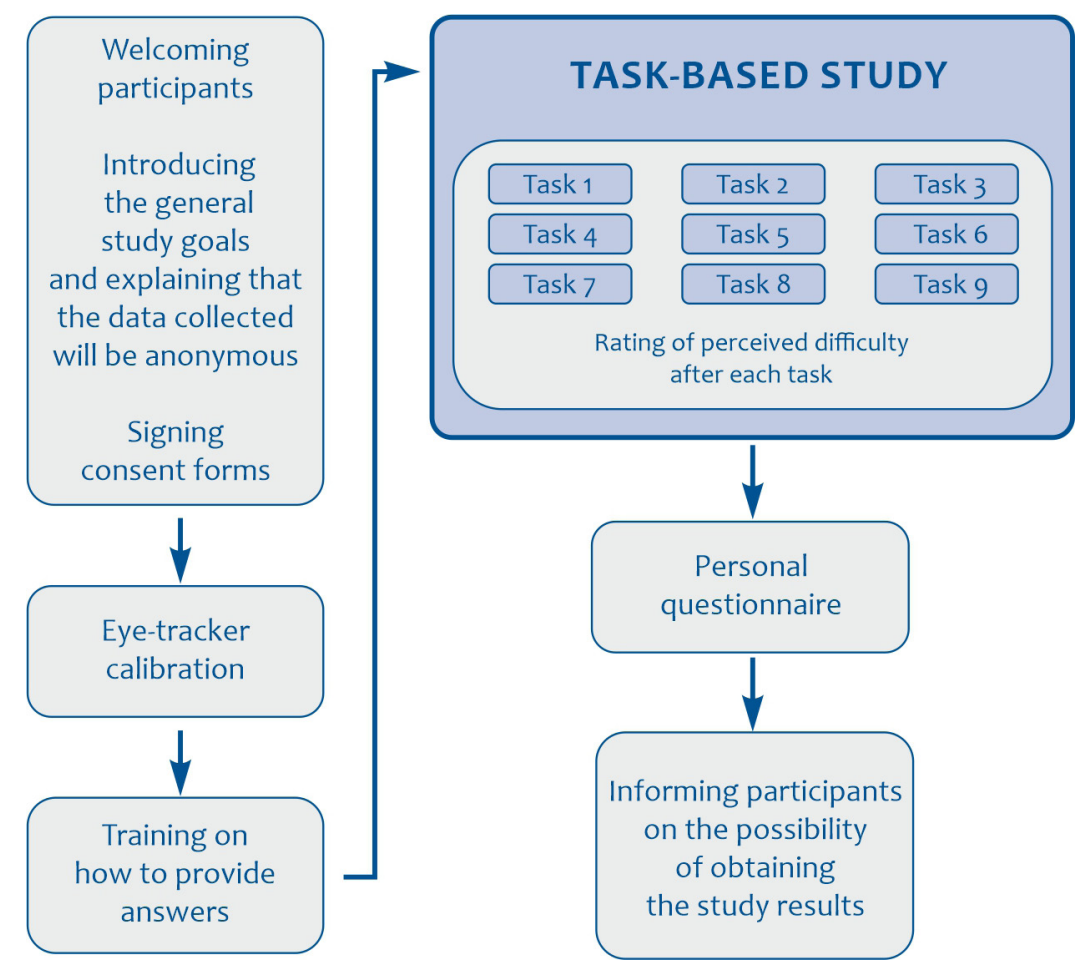

Figure 4. The study procedure

Source: own elaboration

Data analysis

After verifying the quality of the eye-tracking data, the data collected from one participant were excluded since they had weighted gaze samples below the threshold of $80 \%$. Therefore, in the analysis stage, the data collected from 15 participants were included.

The eye-tracking data were analysed in Tobii Studio v. 3.4.8. In order to calculate the eye-tracking metrics, the screen was divided into two AOls: a map and a legend. The calculated eyetracking metrics (fixation duration), as well as other performance metrics (answer time, answer accuracy, rating of difficulty) were analysed in SPSS (PS IMAGO PRO 7.0) software. In order to compare answer time and rating of difficulty, the Friedman test for dependent samples was applied, whereas for answer accuracy the Q Cochran test for dependent samples was used.

Results

Answer accuracy, time, and rating of difficulty

The Friedman test for dependent samples showed that there were statistically significant differences between answer accuracy regardless of tasks (and at all levels of complexity) when using M1v, M2v and M4v maps $\left(X_{F}^{2}(2)=11.561, p<0.01\right)$. The post hoc Wilcoxon signed-rank test with Bonferroni-adjusted alpha level showed that answer accuracy using the simplest $\mathrm{M} 1 \mathrm{v}$ was significantly higher than using the most complex M4v. The average answer time for all nine tasks was not significantly different between map types $\left(X_{F}^{2}(2)=3.733, p>0.05\right)$. Whereas ratings of task difficulty reflected the results of answer accuracy, tasks were differently rated with regard to their difficulty depending on what map type was used $\left(X_{F}^{2}(2)=7.132, p<0.05\right)$, and the post hoc test only showed differences - similar to answer accuracy - between M1v and M4v.

Next, more detailed analyses were conducted with regard to the level of task complexity. We analysed three metrics (answer time, answer accuracy and rating of task difficulty) for each task type: extracting value, namely the task referring to one variable (T1v); locating the areas with regard to values of two variables (T2v); and finding extremums with regard to four variables (T4v). Figure 5 presents an accuracy answer for each task type: in all tasks the accuracy was the highest in each task type when the M1v was used. Cochran's $Q$ test showed that the accuracy differed significantly only in the case of simple T1v tasks $\left(X^{2}(2)\right.$ $=6.5, p<0.05)$. Similar to the analysis of all tasks, the post hoc test showed that answer accuracy differed significantly only between univariate M1v maps and the four-variate M4v map (Table 2).

Answer time did not change between participants using different map types at each of the task complexity levels (Fig. 6; Table 3). The rating of difficulty reflected the results for answer accuracy (Fig. 7; Table 4). The Friedman test showed that differences were significant on the level of $\operatorname{T1V}\left(X^{2}(2)=11.886\right.$, $p<0.01$ ), between M1v and M4v.

\section{Fixation duration analysis}

In order to support the usability performance metrics results collected, we also analysed eye-tracking data collected while solving the given tasks. An initial data overview revealed concerning the different levels of task complexity, we conducted in-depth eye-tracking data analysis with regard to task types.

First, we checked how attention is split across the viewed maps and where the areas of relative increased fixations are located. The heatmaps show that attention, expressed in the higher density of fixation, is distributed differently between map types and when solving different task types (Fig. 8). The area where the question was presented (upper right corner) received similar attention between all task and map types, but the difference between the areas of legends and maps is visible on heatmaps. Some tasks differed considerably with regard to attention placed on the map - for example, compare colour value 
MISCELLANEA GEOGRAPHICA - REGIONAL STUDIES ON DEVELOPMENT

Vol. 25 • No. 4 • 2021 • pp. 259-271 • ISSN: 2084-6118 • DOI: 10.2478/mgrsd-2020-0068

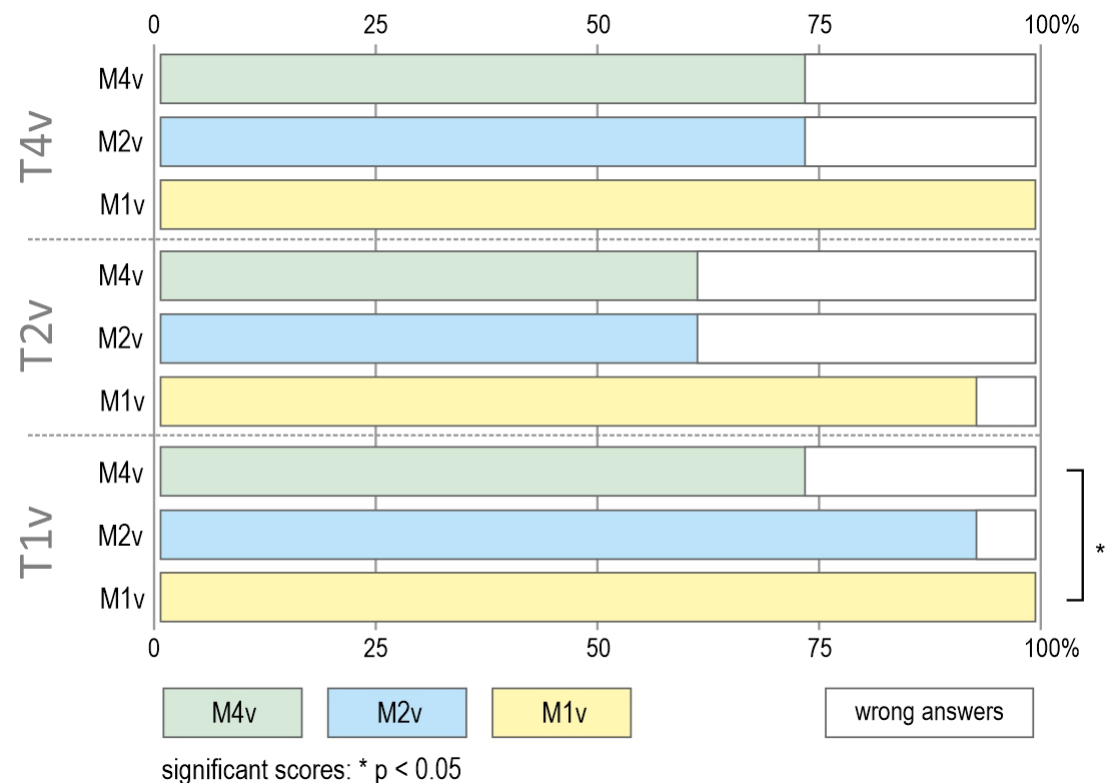

Figure 5. Answer accuracy of participants when using different multivariate map types Source: own elaboration

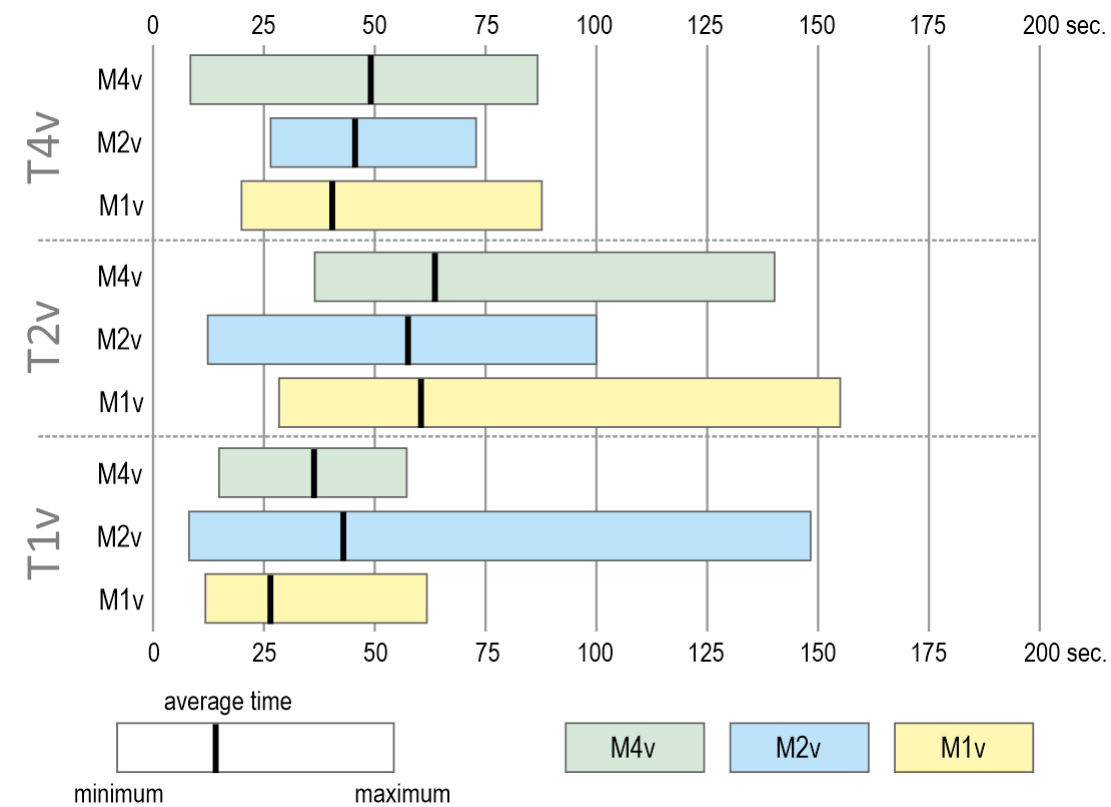

Figure 6. Answer time of participants when using different multivariate map types Source: own elaboration

on map area for T2v (middle row) between M1v (left column) and M2v (middle column). Similarly, differences were noted in the attention given to legends - for example, the colour lightness on legends for T4 $\mathrm{v}$ (bottom row) between M2v (middle column) and M4v (right column).

In order to compare data in a quantitative way, we calculated fixation duration on a map with a legend ( $\mathrm{AOI}$ map and $\mathrm{AOI}$ legend) when solving tasks of different types (Table 5, Figure 9). First, we decided to match the AOls of the legend and the map, since we wanted to get an insight into how working with the whole map differs between tested maps. Analysis of the eye-tracking metric partly repeated the results of the accuracy and difficulty metrics. The Friedman test for dependent samples showed that there were statistically significant differences between fixation durations on maps with legends between participants, while solving tasks referring to one variable $(\mathrm{T} 1 \mathrm{v})\left(\mathrm{X}_{\mathrm{F}}^{2}(2)=12.133\right.$, $p<0.01$; Table 5$)$. The post hoc test showed significantly longer fixation durations for participants using $M 4 v$ than for those using M1 $v$ for these tasks, but also significantly longer fixation durations for participants using M2v than for those using M1v (Table 5, Figure 9). Additionally, unlike performance metrics discussed in section 5.1 , in the case of T4v there were statistically significant 
Table 2. Accuracy of different task types using the three tested maps

\begin{tabular}{|c|c|c|c|c|c|c|c|}
\hline Task type & Map type & $\begin{array}{c}\text { Accuracy } \\
\text { rate } \%\end{array}$ & $\begin{array}{c}\text { Cochran's } \\
\mathbf{Q}\end{array}$ & $p$ & $\begin{array}{l}\text { post hoc } \\
\text { groups }\end{array}$ & $\begin{array}{l}\text { Bonferroni } \\
\text { post hoc }\end{array}$ & $p$ \\
\hline $\mathrm{T} 4 \mathrm{v}$ & $\begin{array}{l}\text { M4v } \\
\text { M2v } \\
\text { M1v }\end{array}$ & $\begin{array}{c}73.33 \\
73.33 \\
100.00\end{array}$ & 4.000 & 0.135 & - & - & - \\
\hline $\mathrm{T} 2 \mathrm{v}$ & $\begin{array}{l}\text { M4v } \\
\text { M2v } \\
\text { M1v }\end{array}$ & $\begin{array}{l}60.00 \\
60.00 \\
93.33\end{array}$ & 4.545 & 0.103 & - & - & - \\
\hline $\mathrm{T} 1 \mathrm{v}$ & $\begin{array}{l}\text { M4v } \\
\text { M2v } \\
\text { M1v }\end{array}$ & $\begin{array}{c}73.33 \\
93.33 \\
100.00\end{array}$ & 6.500 & 0.039 * & $\begin{array}{l}M 4 v-M 2 v \\
M 2 v-M 1 v \\
M 1 v-M 4 v\end{array}$ & $\begin{array}{l}-1.837 \\
-0.612 \\
-2.449\end{array}$ & $\begin{array}{c}0.199 \\
1.000 \\
0.043 \text { * }\end{array}$ \\
\hline
\end{tabular}

Source: own elaboration

Table 3. Answer time while solving different task types using the three tested maps

\begin{tabular}{|c|c|c|c|c|c|c|c|c|}
\hline Task type & Map type & M (sec.) & SD & $\begin{array}{l}\text { Friedman's } \\
\text { Fr }\end{array}$ & p & $\begin{array}{l}\text { post hoc } \\
\text { groups }\end{array}$ & $\begin{array}{l}\text { Bonferroni } \\
\text { post hoc }\end{array}$ & $p$ \\
\hline $\mathrm{T} 4 \mathrm{v}$ & $\begin{array}{l}M 4 v \\
\text { M2v } \\
\text { M1v }\end{array}$ & $\begin{array}{l}49.44 \\
43.99 \\
39.58\end{array}$ & $\begin{array}{l}20.003 \\
13.300 \\
21.145\end{array}$ & 3.733 & 0.155 & - & - & - \\
\hline $\mathrm{T} 2 \mathrm{v}$ & $\begin{array}{l}\text { M4v } \\
\text { M2v } \\
\text { M1v }\end{array}$ & $\begin{array}{l}66,71 \\
57.27 \\
59.86\end{array}$ & $\begin{array}{l}25.925 \\
24.782 \\
32.335\end{array}$ & 3.733 & 0.155 & - & - & - \\
\hline T1v & $\begin{array}{l}\text { M4v } \\
\text { M2v } \\
\text { M1v }\end{array}$ & $\begin{array}{l}35.89 \\
44.48 \\
27.32\end{array}$ & $\begin{array}{l}12.147 \\
37.582 \\
15.248\end{array}$ & 2.133 & 0.344 & - & - & - \\
\hline
\end{tabular}

Source: own elaboration

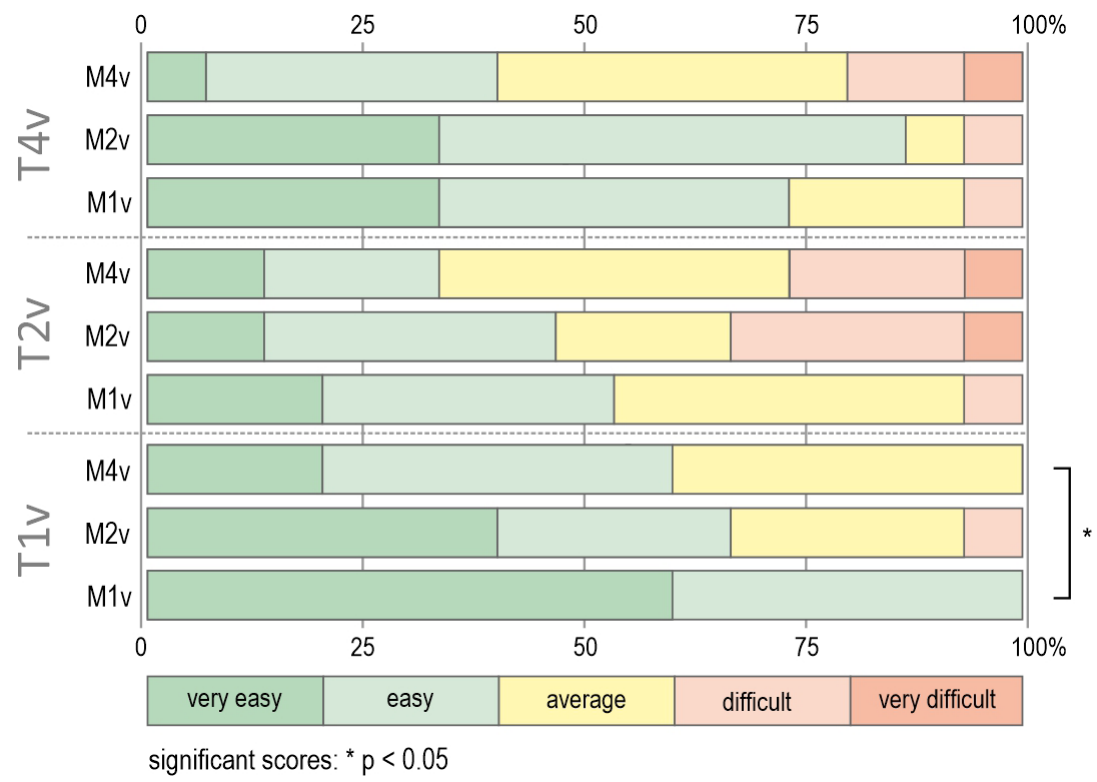

Figure 7. Rating of task difficulty after using the three tested maps

Source: own elaboration 
MISCELLANEA GEOGRAPHICA - REGIONAL STUDIES ON DEVELOPMENT

Vol. 25 • No. 4 • 2021 • pp. 259-271 • ISSN: 2084-6118 • DOI: 10.2478/mgrsd-2020-0068

Table 4. Rating of task difficulty after using the three tested maps

\begin{tabular}{|c|c|c|c|c|c|c|c|c|}
\hline Task type & Map type & M & SD & $\begin{array}{c}\text { Friedman's } \\
\text { Fr }\end{array}$ & $p$ & $\begin{array}{l}\text { post hoc } \\
\text { groups }\end{array}$ & $\begin{array}{l}\text { Bonferroni } \\
\text { post hoc }\end{array}$ & p \\
\hline $\mathrm{T} 4 \mathrm{v}$ & $\begin{array}{l}\text { M4v } \\
\text { M2v } \\
\text { M1v }\end{array}$ & $\begin{array}{l}2.80 \\
1.87 \\
2.00\end{array}$ & $\begin{array}{l}0.262 \\
0.215 \\
0.239\end{array}$ & 8,619 & 0.013 * & $\begin{array}{l}M 4 v-M 2 v \\
M 2 v-M 1 v \\
M 1 v-M 4 v\end{array}$ & $\begin{array}{c}2.373 \\
-0.639 \\
1.734\end{array}$ & $\begin{array}{l}0.053 \\
1.000 \\
0.249\end{array}$ \\
\hline $\mathrm{T} 2 \mathrm{v}$ & $\begin{array}{l}\text { M4v } \\
\text { M2v } \\
\text { M1v }\end{array}$ & $\begin{array}{l}2.80 \\
2.80 \\
2.33\end{array}$ & $\begin{array}{l}0.327 \\
0.312 \\
0.232\end{array}$ & 2.476 & 0.290 & - & - & - \\
\hline T1v & $\begin{array}{l}\text { M4v } \\
\text { M2v } \\
\text { M1v }\end{array}$ & $\begin{array}{l}2.20 \\
2.00 \\
1.40\end{array}$ & $\begin{array}{l}0.200 \\
0.258 \\
0.131\end{array}$ & 11.886 & 0.003 ** & $\begin{array}{l}M 4 v-M 2 v \\
M 2 v-M 1 v \\
M 1 v-M 4 v\end{array}$ & $\begin{array}{l}0.730 \\
1.826 \\
2.556\end{array}$ & $\begin{array}{c}1.000 \\
0.204 \\
0.032 \text { * }\end{array}$ \\
\hline
\end{tabular}

\section{Source: own elaboration}
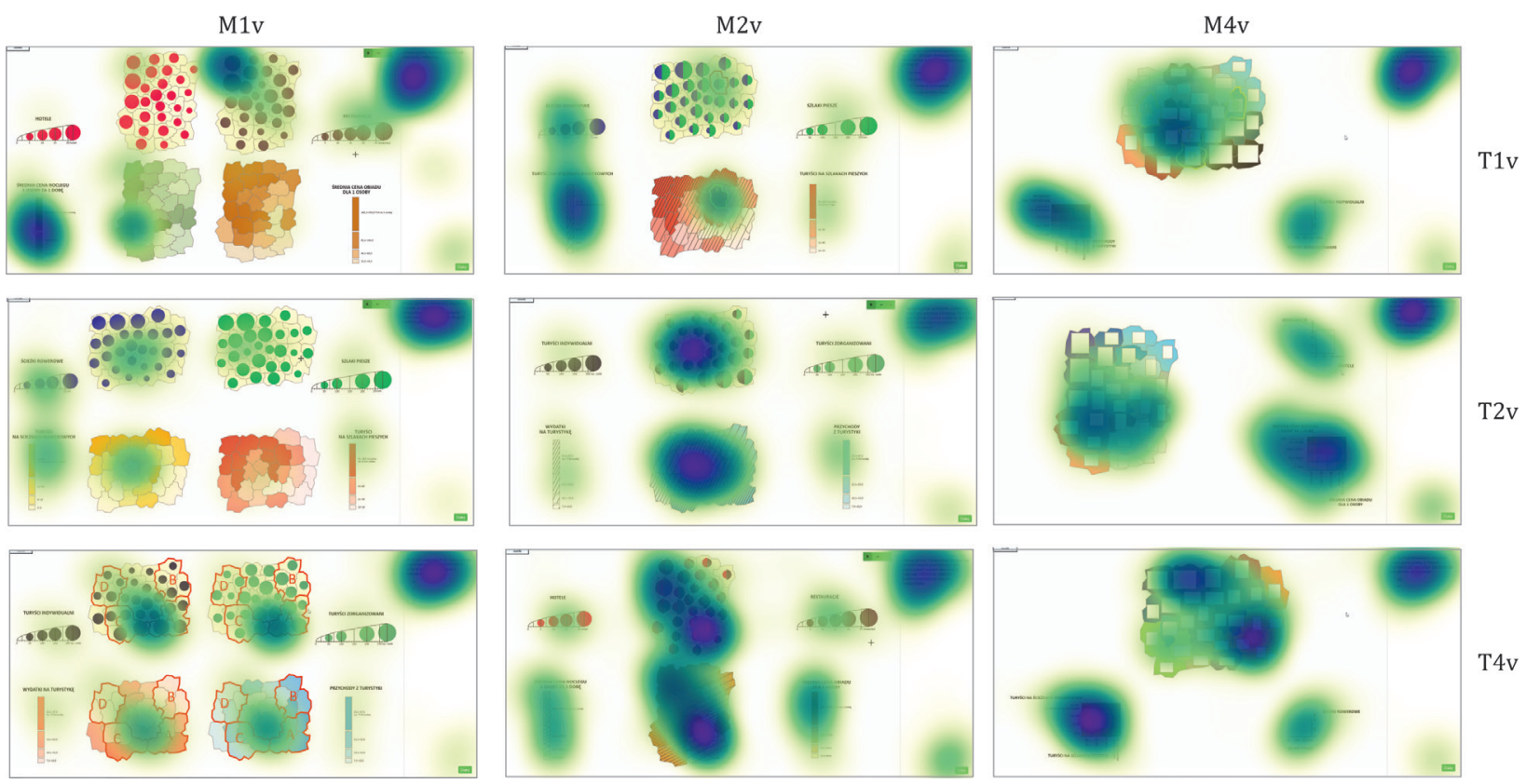

Figure 8. Heatmaps showing visual attention distribution when solving different task types (in rows) using the three tested map types (in columns)

Source: own elaboration

differences $\left(X_{F}^{2}(2)=8.533, p<0.05\right)$ when searching for extremes of four variables: longer fixation duration was noted for M4v than for M1v.

In the next step, we analysed how visual attention was split between the map itself and the map legend (analysis of $\mathrm{AOI}$ map, and AOI legend separately). We investigated whether the attention given to a map and to a legend differs depending on the map type used (Tables 6 and 7, Figures 10 and 11). In the case of map area, again, the simplest tasks T1v resulted in differences between participants using different maps $\left(X_{F}^{2}\right.$ $(2)=6.933, p<0.05)$. In contrast to previous analysis, the post hoc test showed that fixation duration on the map itself, when using M1v, was significantly shorter than when using M2v. This result was not reflected in fixations on legends: there were no significant differences between participants using different map types. Unlike previously analysed metrics (answer accuracy, answer time, difficulty, fixation duration for both map and legend), for tasks referring to two variables (T2v), the differences were statistically significant with regard to fixation duration on the map alone $\left(X_{F}^{2}(2)=6.933, p<0.05\right)$ and fixation duration on the legend $\left(X_{F}^{2}(2)=14.533, p<0.001\right)$. In the case of map area, the post hoc test showed that while solving $T 2 v$, there were significantly longer fixations on the map itself when using $M 2 v$ than when using $M 4 v$. Interestingly, this difference was not significant between the univariate M1v and the most complex M4v map. Whereas in the case of the legend, the difference was significant between fixation durations while using M2v and M4v as well as between M1v and M4v.

While solving the most complex tasks $\mathrm{T} 4 \mathrm{v}$ there was no significant difference between fixation duration on the map itself for the three tested maps but, in the case of fixation duration on the legend, there was $\left(X_{F}^{2}(2)=24.400, p<0.001\right)$. The post hoc test showed the significant differences between fixation duration on the legend for M1v and M4v, as well as M2v and M4v. 
Table 5. Fixation duration on maps with legends while solving different task types using the three tested maps

\begin{tabular}{|c|c|c|c|c|c|c|c|c|}
\hline Task type & Map type & M (sec.) & SD & $\begin{array}{c}\text { Friedman's } \\
\text { Fr }\end{array}$ & $\mathbf{P}$ & $\begin{array}{l}\text { post hoc } \\
\text { groups }\end{array}$ & $\begin{array}{c}\text { Bonferroni } \\
\text { post hoc }\end{array}$ & $p$ \\
\hline $\mathrm{T} 4 \mathrm{v}$ & $\begin{array}{l}\text { M4v } \\
\text { M2v } \\
\text { M1v }\end{array}$ & $\begin{array}{l}27.41 \\
20.17 \\
14.66\end{array}$ & $\begin{array}{c}12.036 \\
10.762 \\
7.973\end{array}$ & 8.533 & 0.014 * & $\begin{array}{l}M 4 v-M 2 v \\
M 2 v-M 1 v \\
M 1 v-M 4 v\end{array}$ & $\begin{array}{l}1.461 \\
1.461 \\
2.921\end{array}$ & $\begin{array}{c}0.432 \\
0.432 \\
0.010 * *\end{array}$ \\
\hline $\mathrm{T} 2 \mathrm{v}$ & $\begin{array}{l}\text { M4v } \\
\text { M2v } \\
\text { M1v }\end{array}$ & $\begin{array}{l}31.86 \\
32.97 \\
21.10\end{array}$ & $\begin{array}{l}14.368 \\
18.868 \\
15.902\end{array}$ & 3.333 & 0.189 & - & - & - \\
\hline $\mathrm{T} 1 \mathrm{v}$ & $\begin{array}{l}\text { M4v } \\
\text { M2v } \\
\text { M1v }\end{array}$ & $\begin{array}{l}16.21 \\
21.04 \\
10.71\end{array}$ & $\begin{array}{c}5.552 \\
16.389 \\
5.249\end{array}$ & 12.133 & 0.002 ** & $\begin{array}{l}M 4 v-M 2 v \\
M 2 v-M 1 v \\
M 1 v-M 4 v\end{array}$ & $\begin{array}{l}-0.183 \\
3.104 \\
2.921\end{array}$ & $\begin{array}{c}1.000 \\
0.006 \text { ** } \\
0.010 \text { ** }\end{array}$ \\
\hline
\end{tabular}

Source: own elaboration

Table 6. Fixation duration on map AOI while using the three tested maps

\begin{tabular}{|c|c|c|c|c|c|c|c|c|}
\hline Task type & Map type & M (sec.) & SD & $\begin{array}{c}\text { Friedman's } \\
\text { Fr }\end{array}$ & $\mathbf{P}$ & $\begin{array}{l}\text { post hoc } \\
\text { groups }\end{array}$ & $\begin{array}{l}\text { Bonferroni } \\
\text { post hoc }\end{array}$ & $p$ \\
\hline $\mathrm{T} 4 \mathrm{v}$ & $\begin{array}{l}\text { M4v } \\
\text { M2v } \\
\text { M1v }\end{array}$ & $\begin{array}{l}15.25 \\
14.66 \\
12.57\end{array}$ & $\begin{array}{l}7.269 \\
8.488 \\
7.564\end{array}$ & 0.933 & 0.627 & - & - & - \\
\hline $\mathrm{T} 2 \mathrm{v}$ & $\begin{array}{l}\text { M4v } \\
\text { M2v } \\
\text { M1v }\end{array}$ & $\begin{array}{l}10.25 \\
23.81 \\
10.69\end{array}$ & $\begin{array}{c}5.159 \\
16.415 \\
7.043\end{array}$ & 6.933 & 0.031 * & $\begin{array}{l}M 4 v-M 2 v \\
M 2 v-M 1 v \\
M 1 v-M 4 v\end{array}$ & $\begin{array}{c}-2.556 \\
1.826 \\
-0.730\end{array}$ & $\begin{array}{c}0.032 \text { * } \\
0.204 \\
1.000\end{array}$ \\
\hline $\mathrm{T} 1 \mathrm{v}$ & $\begin{array}{l}\text { M4v } \\
\text { M2v } \\
\text { M1v }\end{array}$ & $\begin{array}{c}7.64 \\
10.52 \\
5.38\end{array}$ & $\begin{array}{c}4.738 \\
7.918 \\
3.309\end{array}$ & 6.933 & 0.031 * & $\begin{array}{l}M 4 v-M 2 v \\
M 2 v-M 1 v \\
M 1 v-M 4 v\end{array}$ & $\begin{array}{c}-1.826 \\
2.556 \\
0.730\end{array}$ & $\begin{array}{c}0.204 \\
0.032 \text { * } \\
1.000\end{array}$ \\
\hline
\end{tabular}

Source: own elaboration

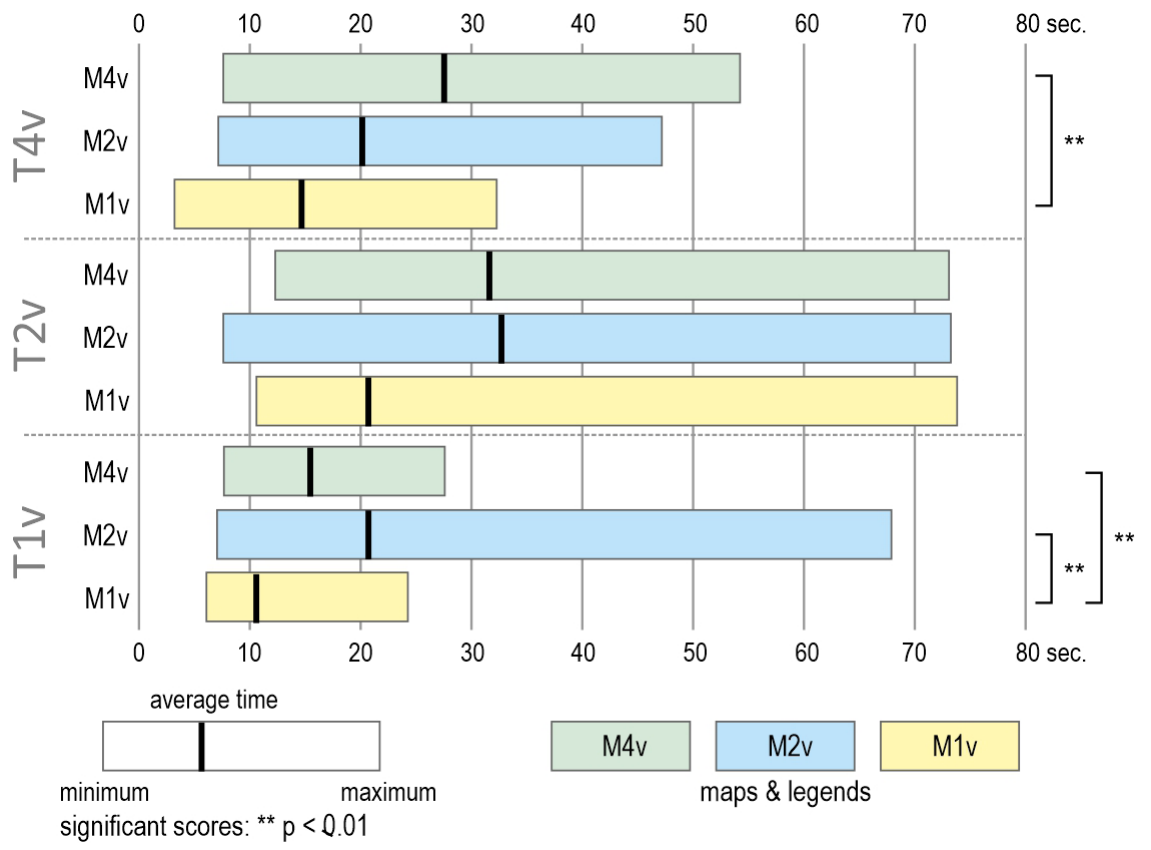

Figure 9. Fixation duration on maps with legends while using the three tested maps

Source: own elaboration 


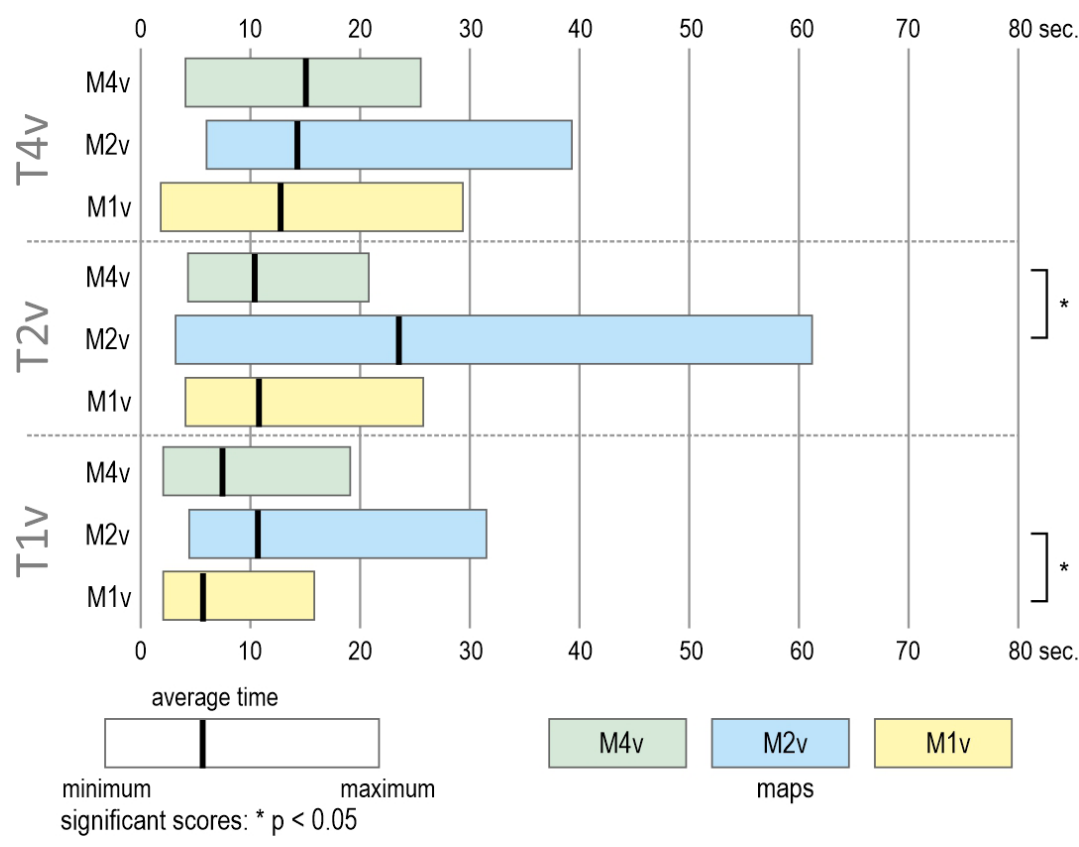

Figure 10. Fixation duration on map AOI while using the three tested maps Source: own elaboration

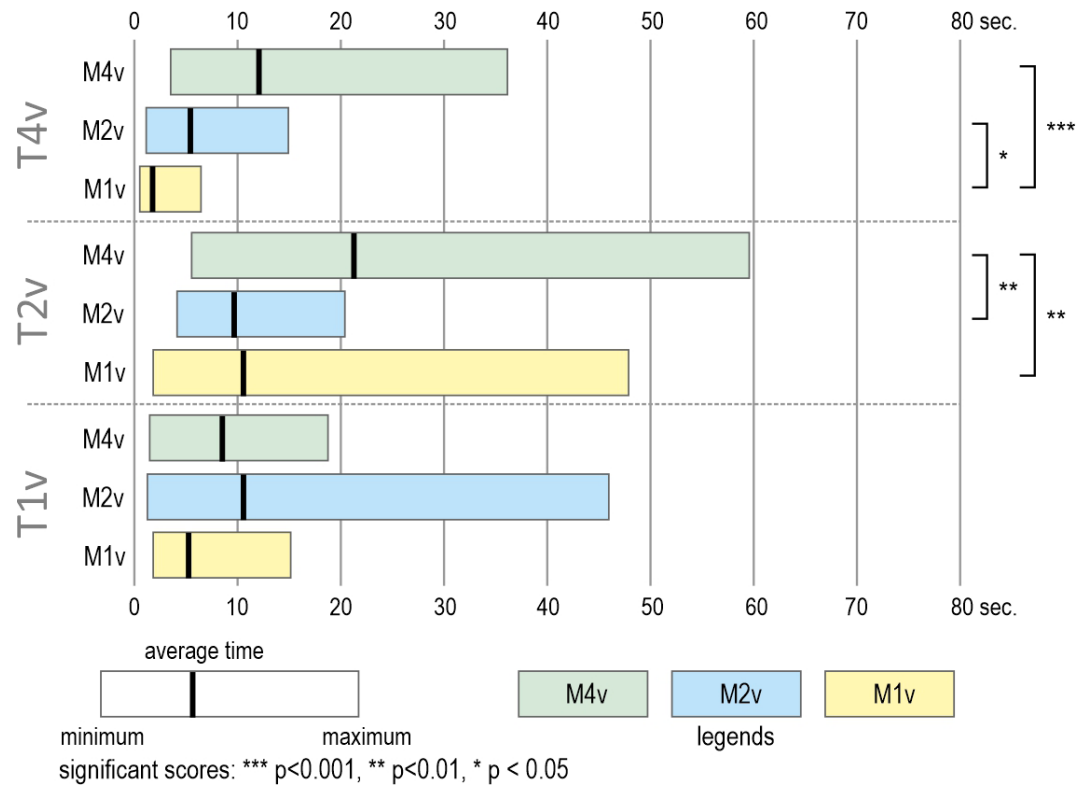

Figure 11. Fixation duration on legend AOI while using the three tested maps Source: own elaboration

Finally, we compared the share of fixation duration on the whole map area, taken by fixation on a map legend and on a map itself (Figure 12). Similar to Šašinka et al. (2019), we interpreted the higher share of fixation on the legend as a higher effort being made to decode the map. We analysed task types (rows in the left part of figure 12) and map types (columns in the left part of figure 12) separately. The calculated values for particular participants were then ordered by the increasing share of fixation on the legend. When solving the simplest task, T1v, the share was similar for all participants, with no visible difference between map types. However, when solving more complex tasks, T2 $v$ and $\mathrm{T} 4 \mathrm{v}$, there is a visibly higher share of fixations on the legend of $\mathrm{M} 4 \mathrm{v}$ than on other maps tested (see the right column in figure 12). Interestingly, the intrinsic M4v map turned out to be the most difficult to decode even when solving tasks referring to many variables at one time. Moreover, in the case of complex T4v, the share spent on examining the legend for simple univariate maps M1v was the lowest, whereas the result for M2v in tasks $\mathrm{T} 2 \mathrm{v}$ is more intuitive: the correspondence between the number of presented variables on the map and the number of searched 
Table 7. Fixation duration on legend AOI while using the three tested maps

\begin{tabular}{|c|c|c|c|c|c|c|c|c|}
\hline Task type & Map type & M (sec.) & SD & $\begin{array}{l}\text { Friedman's } \\
\text { Fr }\end{array}$ & $p$ & $\begin{array}{l}\text { post hoc } \\
\text { groups }\end{array}$ & $\begin{array}{l}\text { Bonferroni } \\
\text { post hoc }\end{array}$ & $p$ \\
\hline $\mathrm{T} 4 \mathrm{v}$ & $\begin{array}{l}\text { M4v } \\
\text { M2v } \\
\text { M1v }\end{array}$ & $\begin{array}{l}12.16 \\
5.51 \\
2.10\end{array}$ & $\begin{array}{l}8.750 \\
3.844 \\
1.453\end{array}$ & 24.400 & $<0.001 * * *$ & $\begin{array}{l}M 4 v-M 2 v \\
M 2 v-M 1 v \\
M 1 v-M 4 v\end{array}$ & $\begin{array}{l}2.191 \\
2.739 \\
4.930\end{array}$ & $\begin{array}{c}0.0850 .019 \text { * } \\
0.000 \text { *** }\end{array}$ \\
\hline $\mathrm{T} 2 \mathrm{v}$ & $\begin{array}{l}\text { M4v } \\
\text { M2v } \\
\text { M1v }\end{array}$ & $\begin{array}{c}21.61 \\
9.16 \\
10.40\end{array}$ & $\begin{array}{c}12.237 \\
4.566 \\
10.878\end{array}$ & 14.533 & $<0.001^{* * *}$ & $\begin{array}{l}M 4 v-M 2 v \\
M 2 v-M 1 v \\
M 1 v-M 4 v\end{array}$ & $\begin{array}{c}3.469 \\
-0.365 \\
3.104\end{array}$ & $\begin{array}{c}0.002 \text { ** } \\
1.000 \\
0.006 \text { ** }\end{array}$ \\
\hline T1v & $\begin{array}{l}\text { M4v } \\
\text { M2v } \\
\text { M1v }\end{array}$ & $\begin{array}{c}8.56 \\
10.52 \\
5.33\end{array}$ & $\begin{array}{c}5.669 \\
12.600 \\
3.933\end{array}$ & 0.533 & 0.766 & - & - & - \\
\hline
\end{tabular}

\section{Source: own elaboration}

M1v

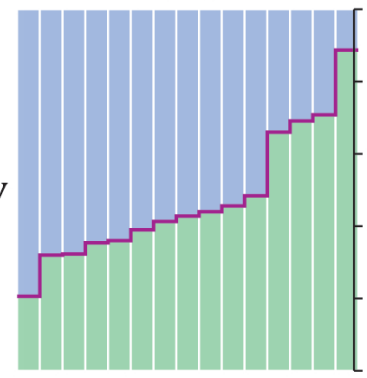

T2v
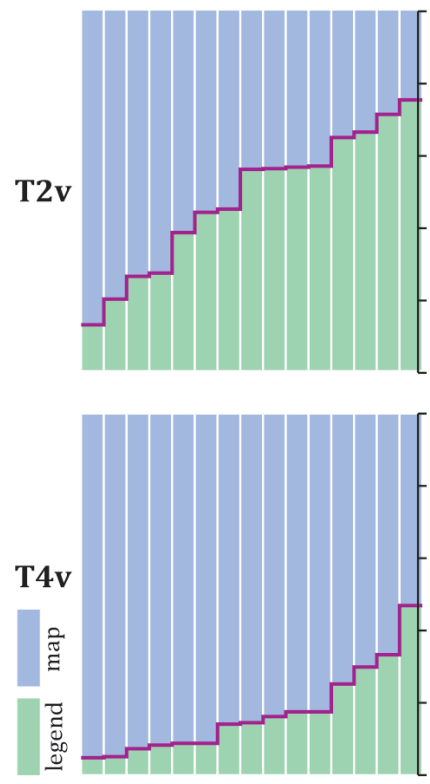

M2v
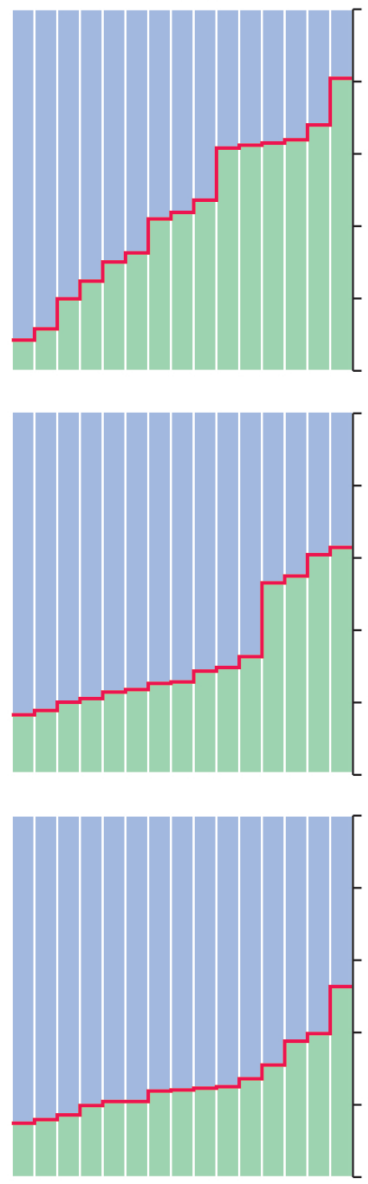

\section{M4v}
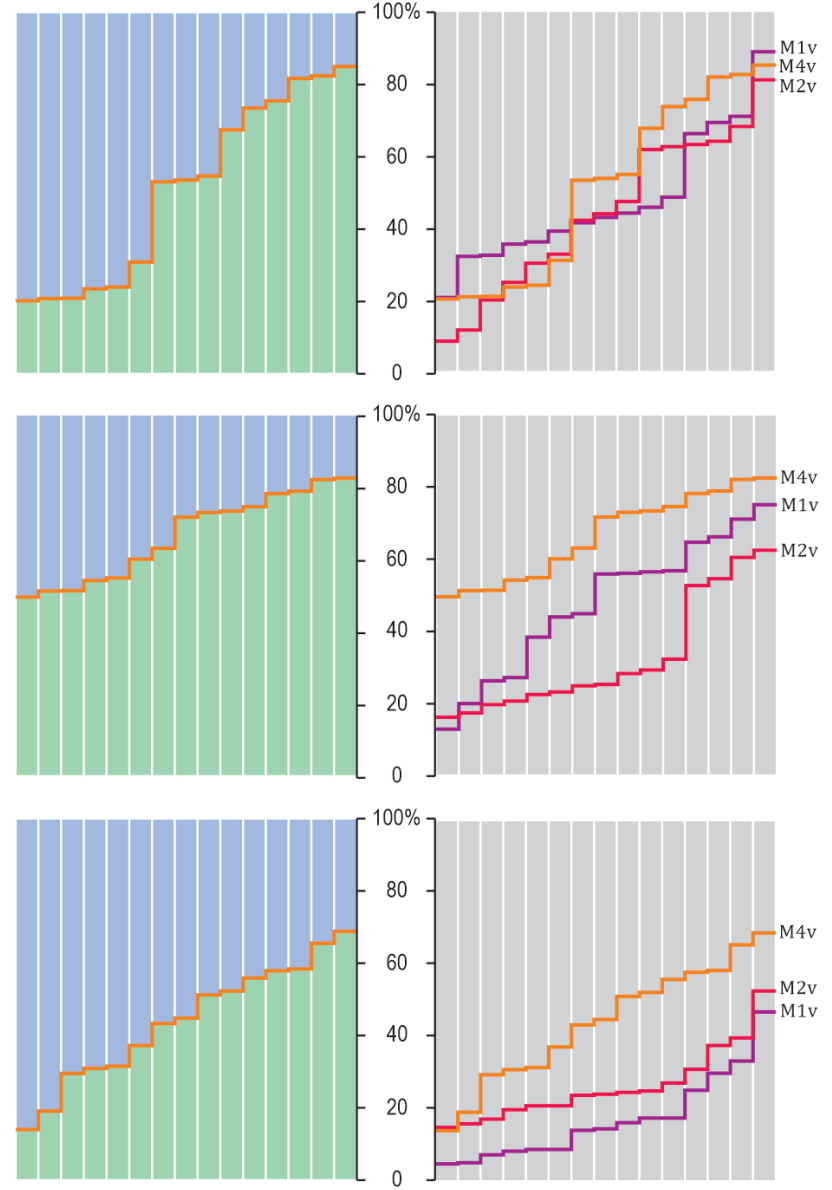

Figure 12. The share of fixation durations on map itself and on map legend Source: own elaboration

variables resulted in the lowest share of fixation spent on decoding the map legend.

\section{Discussion}

The results showed that for expert participants, both designs of multivariate mapping (extrinsic and intrinsic) are of similar suitability for solving tasks of different complexity. Moreover, in the majority of tasks, accuracy, answer time, and difficulty while using multivariate maps (M2v and M4v) were similar compared to univariate maps (M1v), and no consistent statistically significant differences were noted. The high level of literacy enables them to extract the information of different kinds needed, from bivariate and four-variate maps, with similar effectiveness, efficiency and perceived difficulty. The difference (in accuracy and difficulty only) 
is only visible when extracting a separable variable (T1v) from a complex four-variate map (M4v) applying integral variables compared with a simple univariate map (M1v), which supports results of Šašinka $(2019,2021)$ and Nelson $(1999,2000 a, 2000 b)$. But they still needed a similar amount of time. Whereas, concerning all of the metrics, we did not find differences between univariate (M1v) and bivariate maps (M2v) using extrinsic design. This suggests that for experts the use of bivariate maps with separate visual variables is convenient and does not affect performance negatively.

Analysis of eye tracking provided more nuances in the differences between the tested map types. It showed that, even though the results were similar, the effort involved in solving the tasks was higher. For instance, interestingly, the answer time did not differ in T1v and T4v, whereas fixation duration did.

The eye-tracking data analysis confirmed the differences shown by answer accuracy and perceived task difficulty: significantly higher effort was observed when extracting information concerning one separable from a four-variate map (M4v) than from univariate maps (M1v). This confirms the opinions of Nelson (1999, 2000a, 2000b) and Šašinka et al. $(2019,2021)$ that intrinsic maps with integral visual variables do not facilitate reference to a single variable. Additionally, eye-tracking data analysis showed differences while solving tasks that refer to more than one variable: in $\mathrm{T} 2 \mathrm{v}$ concerning fixation duration on the map (Figure 10), and in T2v in the case of the legend AOI (Figure 11).

A comparison of the share of fixation duration on the map and on the legend provided similar results to Šašinka et al. (2021). Intrinsic maps (M4v) resulted in a higher share of fixation duration on the map (Figure 12), suggesting more effort is given to decoding the mapped information. This was visible especially in the more complex tasks, which referred to many variables (see $T 2 v$ and $T 4 v$ in Figure 12). The result is thus in opposition to the assumed purpose of multivariate maps: four-variate intrinsic maps resulted in greater effort to solve more complex tasks. It also suggests that there is no direct relationship with regard to the suitability of a map between the number of mapped variables and the number of variables presented on a single map. Only in the case of bivariate maps (M2v), for tasks involving two variables (T2v), was the share of legend the lowest compared to other tested map types (Figure 12). However, the other types of tasks (when referring to one and to four variables) resulted in a different tendency: for simple tasks, all of the maps had a similar share of fixation duration, whereas for complex tasks and referring to four variables, the lowest share of fixation on legend was observed in the case of a series of univariate maps.

The bivariate extrinsic maps with configural and separable visual variables (M2v) did not differ in the majority of analysed metrics from the simple univariate maps (M1v). Therefore, applying a bivariate extrinsic map instead of a univariate series of maps should not affect the performance of experienced users. The results showed that the series of univariate maps (M1v) can be helpful for both simple (T1v) and complex tasks (T2v, $\mathrm{T} 4 \mathrm{v}$ ). However, four-variate maps (M4v) did not prove such wide usability with regard to task complexity, whereas bivariate maps with separable variables (M2v) turned out to be a competitive solution for both simple (T1v) and complex tasks (T2v, T4v). Therefore, the cognitive load connected with multivariate mapping affected the performance of expert users only in the case of the four-variate intrinsic map.

\section{Conclusions}

The study conducted here aimed to compare the effect of applying three designs of multivariate mapping to tasks of different complexity. Expert users employed the tested maps with similar effects; however, the effort put in solving the tasks differed. In most cases the most challenging solution was a single four-variate intrinsic map, also for complex tasks, as this solution resulted in the highest effort, which was reflected, for example, in the fixation duration on the map with a legend or on the share of fixation duration on the legend. The intrinsic design is a challenge even for experienced users but does not significantly affect the results of working with a map.

Our study, as most others, has some limitations. The first one is the number of participants. To combat the limitation, we applied within-subject design, and therefore the compared groups had three times as many participants as would have been the case in a between-subject study design. Even so, we are aware that conclusions should be carefully formulated. Moreover, we applied limited eye-tracking analyses among the many available metrics. We decided to select the fixation duration metric only since we treated eye-tracking data as a support for the evaluation with usability performance metrics. We did not hypothesise on the cognitive processes involved in the use of the maps, the aim of the study being to compare the map designs. Finally, it should be noted that the study concerns a specific map configuration, with specific symbolization methods (choropleth mapping and proportional symbol mapping) and data content. Therefore, transferability of the collected results should be conducted in a careful way. Therefore, more research is needed to better investigate user issues when working with multivariate maps.

We believe that, due to the abundance of data, multivariate maps will still be needed; it is therefore important to make informed decisions when choosing map design. We believe the study conducted here provides input into understanding how to design helpful multivariate maps that might be a useful tool when making decisions on different levels of complexity: from simple to complex ones referring to many variables at once. We thus believe that further investigations and more empirical research, including specific groups of users and specific kinds of data, will enable us to further develop the understanding of multivariate mapping and usage.

\section{Acknowledgements}

This work was supported by the National Science Centre Poland under the grant no. UMO-2016/23/B/HS6/03846.

\section{ORCID}

Jolanta Korycka-Skorupa (D) https://orcid.org/0000-0001-7737-3559 Izabela Gołębiowska (1) https://orcid.org/0000-0002-4307-7054

\section{References}

Brewer, CA \& Campbell, AJ 1998, 'Beyond graduated circles: Varied point symbols for representing quantitative data on maps', Cartographic Perspectives, vol. 29, pp. 6-25.

Carr, D 1991, 'Looking at large data sets using binned data plots' in Computing graphics in statistics, eds A Buja \& P Tukey, Springer-Verlag, New York, pp. 7-39.

Carr, D, Olson, A \& White, D 1992, 'Hexagon mosaic maps for display of univariate and bivariate geographical data', Cartography and GIS, vol. 19, no. 4, pp. 228-236.

Carstensen, LW 1982. 'A continuous shading scheme for twovariable mapping', Cartographica, vol. 19 , no. 3 , pp. 5370. 
Carstensen, LW 1984, 'Perceptions of the variable similarity of bivariate choroplethic maps', The Cartographic Journal, vol. 21, no. 2, pp. 23-29.

Carstensen, LW 1986a, 'Hypothesis testing using univariate and bivariate choroplethic maps', The American Cartographer, vol. 13 , no. 3, pp. 231-251.

Carstensen, L 1986b, 'Bivariate choropleth mapping: The effects of axis scaling', The American Cartographer vol. 13, no. 1, pp. 27-42.

Cuff, DJ, Pawling, JW \& Blair ET 1984, 'Nested value-by-area cartograms for symbolizing land use and other proportions', Cartographica, vol. 21, no. 4, pp. 1-8.

Dahlberg, R. 1981. Educational needs and problems within the national cartographic system. The American Cartographer, vol. 8, no. 2, pp. 105-114.

Dent, BD, Torguson JS \& Hodler TW, 2009, Cartography: thematic map design, 6th edn, McGraw Hill, New York.

Elmer, ME 2013, 'Symbol considerations for bivariate thematic maps', in Proceedings of the 26th International Cartographic Conference (ICC). International Cartographic Association: Dresden. Available from: <http://icaci.org/files/documents/ ICC_proceedings/ICC2013/ extendedAbstract/278 proceeding.pdf $>$ [08 June 2021]

Eyton, JR 1984, 'Complementary-color in two-variable maps', Annals of the Association of American Geographers, vol. 74, no. 3, pp. 477-90.

Fabrikant, SI, Rebich-Hespanha, S, Andrienko, N, Andrienko, G \& Montello DR 2008, 'Novel method to measure inference affordance in static small-multiple map displays representing dynamic processes', The Cartographic Journal, vol. 45, no. 3, pp. 201-215.

Gershon, N 1998, 'Visualization of an imperfect world', IEEE Computer Graphics and Applications, vol. 18, no. 4, pp.43-45.

Huber, S, Sieber, R, Ruegsegger, M \& Hurni, L 2007, 'Multivariate mapping in high quality atlases', in Proceedings of the 23th International Cartographic Conference (ICC). International Cartographic Association: Moscow, pp. 1-10.

Kiik, A, Nyström, M. \& Harrie, L 2017. 'Cartographic design matters - a comparison of thematic polygon design', The Cartographic Journal, vol. 54, no. 1, pp. 24-35.

Korycka-Skorupa, J \& Nowacki, T 2019, 'Cartographic presentation - from simple to complex map', Miscellanea Geographica - Regional Studies on Development, vol. 23, no. 1, pp. 16-22.

Kraak, MJ, Roth, RE, Ricker, B, Kagawa, A, Le Sourd, G 2020, Mapping for a Sustainable World. The United Nations: New York.

Lavin, S \& Archer JC 1984, 'Computer-produced unclassed bivariate choropleth maps', The American Cartographer, vol. 11, no. 1, pp. 49-57.

Leonowicz, A 2006, 'Two-variable choropleth maps as a useful tool for visualization of geographical relationship', Geografija, vol. 42, no. 1, pp. 33-37.

Nelson, ES 1999, 'Using selective attention theory to design bivariate point symbols', Cartographic Perspectives, vol. 32, pp. 6-28.

Nelson, ES 2000a 'Designing effective bivariate symbols: the influence of perceptual grouping processes', Cartography and Geographic Information Science, vol. 27 , no. 4, pp. 261-278.

Nelson, ES 2000b 'The impact of bivariate symbol design on task performance in a map setting', Cartographica, vol. 37, no. 4, pp. 61-78.
Nelson, J 2020, 'Multivariate mapping' in The Geographic Information Science \& Technology Body of Knowledge, ed. John P. Wilson. Available from: <https://gistbok.ucgis.org/ bok-topics/multivariate-mapping> [15 June 2021].

Olson, JM 1981, 'Spectrally encoded two-variable maps', Annals of the Association of American Geographers, vol. 71, no. 2, pp. 259-276.

Šašinka, Č, Stachoň, Z, Kubíček, P, Tamm, S, Matas, A \& Kukaňová, M 2019, 'The impact of global/local bias on tasksolving in map-related tasks employing extrinsic and intrinsic visualization of risk uncertainty maps', The Cartographic Journal, vol. 56, no. 2, pp. 175-191.

Šašinka, Č, Stachoň, Z, Čeněk, J, Šašinková, A, Popelka, S, Ugwitz P \& Lacko, D 2021, 'A comparison of the performance on extrinsic and intrinsic cartographic visualizations through correctness, response time and cognitive processing', PLOS ONE, vol. 16, no. 4.

Slocum, A 1981, 'Analyzing the communicative efficiency of twosectored pie graphs', Cartographica, vol. 18, no. 3, pp. 5365.

Strode, G, Mesev, V, Bleisch, S, Ziewitz, K, Reed, F, \& Morgan, JD 2020, 'Exploratory bivariate and multivariate geovisualizations of a social vulnerability index', Cartographic Perspectives, vol. 95, pp. 5-23.

Tufte, E 1990, Envisioning information, Graphics Press, Cheshire, Conn.

Wainer, H \& Francolini, C 1980, 'An empirical inquiry concerning human understanding of two-variable color maps', The American Statistician, vol. 34, pp. 81-93. 